\title{
Analysis of Diversity and Reform of College Physical Education
}

\author{
Jian Xiong \\ Haikou College of Economics, Haikou 571127, China \\ 419985168@qq.com
}

\begin{abstract}
Keywords: Sports teaching, diversified development, reform and innovation, colleges and
\end{abstract} universities

\begin{abstract}
This paper has conducted systematic analysis of teaching models, evaluation methods through documents ,research, practice, lessons learned and other methods to explore diversified development trend of college physical education. We find that the teaching patterns and evaluation method of physical education in colleges and universities are single. So here are the recommendations: we improve the sports curriculum offering in colleges and universities according to the requirements of the development, build a diversified teaching models and evaluation system, and deepen the teaching reform.
\end{abstract}

\section{Introduction}

National Physical Education Curriculum Guiding Outline for Universities is the teaching syllabus and evaluation basis in the new era. The physical education is one of the public compulsory courses in which college students can enhance their physical fitness and health and improve their physical literacy through physical exercise as the main means along with some reasonable physical education. And it is also the main road to fully implement quality education and develop the talents of round-development. The basic goals of physical education curriculum are primarily: sports participation, sports skills, physical health, mental health, social adaptation . The Outline puts forward that the Curriculum Structure should take purposeful, planned, organized extracurricular physical activities ,after-school (social, outdoor) activities, sports training into consideration to establish the course structure with the advantages of internal and external connections

China's economy enjoys a diversified development, and should the sports, which is beneficial to social, economic, cultural and human health services. According to the characteristics of the modern professions, courses and profession we subdivide the need for physical fitness to promote the diversified development of sports education .

\section{Current Situation of College Physical Education Development}

\section{1 single curriculum, small class teaching capacity, narrow range of knowledge theory}

National College Physical Education Curriculum Teaching Guidelines points that we should set up many types of physical education curriculum in accordance with the general requirements of school education and laws of physical education curriculum, and combine the fitness of the culture, selection nature effectiveness, acceptability,ethnicity and so on . We should break the original class-based institution, regrouping class, to meet the needs of different levels, different levels, and different students. And we should put emphasis on the combination of theory and practice, penetrating the relevant theoretical knowledge in sports practice teaching, using a variety of forms and modern teaching methods to expand the sports knowledge and improve their cognitive abilities.

Since the issuance of National Physical Education Curriculum Guiding Outline for Universities by Ministry of Education in 2002 ,the Physical Education in colleges and universities have been undergone ongoing reform, but the intensity of reform is not enough. There is no major change of curriculum reform in essence and the teaching concept of teachers has not changed ,weighing practice-oriented teaching technical skills but neglecting theoretical knowledge. And there is also the divergence of"traditional" teaching and"sheep" teaching. What's more, many sports teachers of colleges and universities neglect the physical education curriculum and the physical education curriculum content are nearly the same as that of high school. We basically set up the courses like swimming, aerobics, football, volleyball, basketball, tai chi, table tennis, badminton and other sports as optional classes while the theoretical teaching is lagging behind; 
classroom teaching content capacity is small,;there is a lack of cross-disciplinary knowledge content and thus the students only master a narrow range of knowledge.

\subsection{Lack of Classroom Teaching Research and Inaccuracy and Mismatches of Sports Terminology Wording}

In sports teaching, teachers lack classroom teaching and research and ignore the conventional norm of sports class.In the lining up,teachers often misuse some command orders,such as "Into the four horizontal teams set" or "into four columns set". The term concept is not accurate, and the language terminology is not standardized. The correct wording should be "four columns", "four horizontal teams", "column" should be understood to stand for about two players tied for the team formed, generally refers to horizontal teams, and "Road" should be around two players standing overlap formed team, generally refers to the column. When lining up team should try to achieve the "three avoidance", the students face away from the sun and sand in the face, the face of interference around. Formation should be arranged from low to high order, but this is often overlooked in the teaching, which makes students have $s$ vague understanding of formation .The teachers' non-standard teaching in an unclear gesture, not loud whistle make the classroom is not rigorous and students can't focus on classes thus wasting time of classes.

\section{3 lack of bilateral activities of teacher-student interaction and the shortness of playing a leading role for students}

"National College Physical Education Curriculum Teaching Guidelines" points out that we must give full play to the leading role of teachers and the main role of students, promoting open, inquiry-based teaching, efforts and expanding the time and space of the physical education curriculum. Teaching methods to pay attention to personal and diversification, promoting multilateral mutual activities between teachers and students and among students, and strive to improve students 'participation, maximizing the students' creativity. Research should not only focus on teaching, but also strengthen the guidance of learning methods and practice methods to improve students' self-learning ability from practice. "Health First" and "Lifetime Sports" guiding ideology has become the dominant trend of School Sports. However, the arrangements for the general physical education curriculum are more random, and the content is relatively chaotic, ignoring students' perceptions of the physical education, resulting in physical education boring, boring with teaching effect reduced. Teachers lack a clear knowledge of the importance of creating a positive and learning environment. Some colleges still put too much emphasis on organization, discipline, teaching, emphasis on "teaching" rational, testimonies and "learning" orderly, unified etc in physical education. In the classes,teachers seldom interact with students and students seldom interact with students, and they don't fully play their role.What's more the tension of classes suppresses students' interest in learning and subjective initiative .

\subsection{The imperfection of teachers and students evaluation system}

Sports curriculum evaluation involves three aspects of ,namely, student learning, teaching and curriculum construction. Evaluation should dilute the screening and selection capabilities, strengthen the incentive to develop the function,and take the amplitude of the student's progress into the evaluation content. Student learning assessment should be the assessment based on learning results and learning process, including physical fitness and motor skills, cognition, learning attitude and behavior, communication with the spirit of cooperation, affection and other performance.And it can be through student self-assessment, peer assessment and teacher evaluation, etc. However, in reality,we pay much attention to testing the students 'technical skills, ignoring the cultivation of theoretical knowledge and self-organizing ability, without considering the students' abilities, not fully examining students 'learning ability, putting much emphasis on students' technical skills and neglecting students' self assessment and organizational capabilities.

Although some teachers enjoy excellent teaching practical skills but their teaching capacity is weak. They don't know to correctly use teaching methods. They don't know how to record in class and analyze the class after class. They lack of careful observation and understanding of the student's personality, so it will be difficult for them to individualize the students,thus they fail to spur students' learning motivation, having a side effect on classroom teaching.

\subsection{The constraints brought by sports venues and equipment of the physical education curriculum reform}

Sports venues and equipment is an to important material basis to complete the tasks of school sports and the purposes of school sports, and it is also an important yardstick to test the degree of development of school sports. Currently, institutions of higher learning have been enlarging their enrollment,so the sharp increase of the number of students lead a serious shortage of space of movement area per student, affecting the implementation of quality and curriculum reform of college sports teaching in university education. Many schools cannot promote and learn in physical 
education reform due to the constraints of hardware facilities.

\section{Conclusions and Suggestions}

\subsection{Fostering sports talents with complex abilities}

Teachers should have a broad knowledge and theoretical basis of interdisciplinary research in physical education,and teachers should be able to timely and appropriately answer students' questions and doubts. They should update with new ideas, learn to absorb and draw on knowledge, conduct a comprehensive study on the basis of the existing achievements and create innovative teaching models and teaching methods. We should pay attention to "fault" crisis, and determine strategic approach of the construction of teachers, strengthen teacher' training to improve the professional level of sports teachers and their scientific research ability.We should pay attention to discipline construction, cultivating a number of young backbone teachers or academic leaders with high ideological quality, certain academic attainments, ground to study and team spirit and strong high-level, highly qualification.

We should encourage young teachers with the ability come to the fore, to upgrade their qualifications and title structure, forming a rational academic team, so as to solve the problem of academic Age fault. And we should adopt the method of "helping" role in the formation of good learning and research environment. We also should adopt the "going out" and "bringing in" approach, promoting inter-university academic exchanges between different disciplines, creating learning opportunities for training and academic exchanges at home and abroad, forming a theoretical knowledge base to update the sports teachers, training teachers with interdisciplinary knowledge of structural capacity, planning to develop training teachers from a diversified perspective and training a number of sports personnel with open multi-disciplinary knowledge, multi-disciplinary capability.

\section{2 formulations of teaching objectives and diversified teaching content in accordance with requirements of the times}

Colleges and universities should establish a "health first" guiding ideology,and conduct the curriculum system reform according to the characteristics of talents and the needs of social development, implementing the diversified teaching mode. And we should choose appropriate teaching modes according to physical characteristics and professional characteristics and sports characteristics of male and female students, expand the sports teaching content to adapt to modern society ,reform teaching system, improve teaching methods, teaching structure, rich content of classroom teaching,and improve teaching quality.

We can add some recreational fitness programs associated with the characteristics of modern occupations to integrate the sports events with the modern professions ,thus developing practical and easily-operational sports events with fun, fitness, educational meaning, so that we make the single the physical education diversified. For example, we can create teach the secretarial students who will face much arduous work in office some knowledge to prevent the cervical, lumbar diseases ,design some unarmed aerobics exercise in the limited space of office, and develop some simple and practical fitness programs according to the actual in office,like using the chairs and desks . For those who major in architecture, we can create some hiking and outdoor survival activities and some other sports, helping them quickly adapt to the environment and improve the ability to protect themselves in the future work of field operations to quickly adapt to the environment and to improve the ability to protect themselves. For boys, we can impart some sports irritating and competitive knowledge,and for girls we can create some body sculpting fitness and obesity prevention programs, some lively paced aerobics and stretching exercises, which not only can stimulate students' movement interests, but also meet students' pursuit of bodybuilding physique. We must let students play the main role in the learning process, encourage students to create design fitness programs stimulating students' creativity.

\section{3 highlights of the importance of quality education lifelong physical awareness}

We set up sports courses according to the physical characteristics, athletic ability, interest in sports, professional and employment characteristics of men and women . We take the method of diversified teaching,which is beneficial to the future career, to highlight the quality education according to students and the features of the different kinds of sports . Our purposes are to integrate the ideas of active physical training and happy sports into the university physical education to develop the concept of lifelong physical training . We rationally use the modern teaching methods in the process of physical education to increase the amount of information, make full use of projection, video, computer remedial teaching software, multimedia technology and other modern technologies to create a pleasant educational situation and a relaxing learning environment, 
encouraging the enthusiasm of students to fully mobilize the enthusiasm of students, enabling them to experience the fun, feel the effects and enjoy the results through active participation, thus developing sports-loving, active habits.

\subsection{The diversity of evaluation of students' achievement and teachers' teaching ability}

Reform of university sports teaching appraisal system must focus on the development of a diversified environment to provide a strong support and protection for the university physical education by establishing a perfect diversified teaching evaluation modes, thus promoting continuous progress of college physical education, strengthening the physical Training of College Students and lifelong physical awareness. Sports teachers should focus on the learning and teaching of theoretical knowledge , strengthen theoretical study ,enhance the theoretical level , improve the teaching and research capabilities, conduct in-depth practice, fully implement the unique role of classroom teaching, carefully study the problems of classroom teaching, analyze conscientiously after school, implement the diversified teaching evaluation, improve the teaching methods and improve enhance the effectiveness.

According the level of sports skills of students, we should comprehensively evaluate students promoting students' self-evaluation and mutual evaluation while we conduct the evaluation of teachers,we should focus on the dual nature of teaching and learning, focusing on the theoretical level, the ability to practice, teaching effects, etc. It will be more scientific and objective if we apply the use of third-party evaluation of student's academic level and the teachers' teaching standards.

\subsection{Perfection of sports facilities and building of a diversified teaching fitness sites}

Physical education is a teaching process where teachers teach and students learn, learning and practicing the teaching process closely, and sports equipment and facilities is a prerequisite for Physical Education. Students alone Classroom difficult sport to master technical skills, you need to strengthen after-school practice, the formation of dynamic stereotype, action to achieve proficiency in the use, until the operation automation, sports and fitness in order to develop good habits. Therefore, the school sports facilities into the overall planning of school construction, the use of multiple channels to increase funding, increase fitness equipment and fitness venues to expand the limited space and resources to build a diversified teaching facilities and amateur fitness areas, fully tap and use of natural conditions, local conditions, efforts to improve the site equipment and facilities, improve school conditions.

\section{References:}

[1] Notice of the Ministry of Education on the issuance of "National College Physical Education Curriculum Teaching Guidelines" in [EB / OL]

http://www.moe.edu.cn/publicfiles/business/htmlfiles/moe/moe_28/201001/80824.html

[2] Xie Hui. Under Curriculum Reform of College Sports Teaching Ability Development Research

[J]. Sports and Science, 2010.05.020

[3] Chen child would Factors Influencing the development of university sports teaching our analysis.

[J]. Sports and Science, 2010.01.026

[4] Liu Zhibin. Development and Universities Physical Education Reform Education Resources [J]. Sports and Science, 2012.02.012

[5] reform of college sports in China to explore Ma Jinfeng. [J]. Shandong Institute of Physical Education, 2014.02.020

[6] Qian Jun, etc. Lack of communication and Construction College Physical Education Teaching [J]. Journal of Physical Education, 2010.01

[7] Wei Yong. Research on College Physical Education Teaching Mode Analysis [J]. Shandong Institute of Physical Education, 2010.02.014

[8] Ding Xiaoyan. Development Path of College Physical Education Teaching[J]. Chinese Society of Education, 2015.02 